\title{
Sodium butyrate reduces bovine mammary epithelial cell inflammatory responses induced by exogenous lipopolysaccharide, by inactivating NF-KB signaling
}

\author{
Xudong Sun, ${ }^{1}$ Shengbin Luo, ${ }^{1}$ Chunhui Jiang, ${ }^{1}$ Yan Tang, ${ }^{1}$ Zhijun Cao, ${ }^{2}$ Hongdou Jia, ${ }^{1}$ Qiushi Xu, ${ }^{1}$ \\ Chenxu Zhao, ${ }^{1}$ Juan J. Loor, ${ }^{3}$ and Chuang $\mathrm{Xu}^{1 *}$ \\ ${ }^{1}$ Heilongjiang Provincial Key Laboratory of Prevention and Control of Bovine Diseases, College of Animal Science and Veterinary Medicine, \\ Heilongjiang Bayi Agricultural University, Daqing, Heilongjiang Province 163319, China \\ ${ }^{2}$ State Key Laboratory of Animal Nutrition, College of Animal Science and Technology, China Agricultural University, Beijing 100193, China \\ ${ }^{3}$ Mammalian NutriPhysioGenomics, Department of Animal Sciences and Division of Nutritional Sciences, University of Illinois, Urbana 61801
}

\begin{abstract}
Exogenous molecules derived from catabolic states (e.g., fatty acids, $\beta$-hydroxybutyrate) during periods of stress such as the periparturient period or pathogen challenges [e.g., lipopolysaccharide (LPS)] can trigger an inflammatory response in tissues such as the liver and the mammary gland. Butyrate is one of the major short-chain fatty acids produced in the rumen, and work with non-ruminants has demonstrated that it can alter inflammatory processes. The primary objective of this study was to explore the preventive effect of sodium butyrate (SB) on LPS-induced inflammation in bovine mammary epithelial cells along with underlying molecular mechanisms. Immortalized bovine mammary epithelial cells (MAC-T) were treated with SB (0.1, $0.25,0.5,1,2$, or $5 \mathrm{mM}$ ) or with the histone deacetylase inhibitor trichostatin A (TSA; $6.25,12.5,25$, or $50 \mathrm{nM}$ ) for $18 \mathrm{~h}$, followed by a challenge with $1 \mu \mathrm{g} / \mathrm{mL}$ LPS for an additional $6 \mathrm{~h}$. Pretreatment with SB prevented increase in apoptosis of LPS-challenged MAC-T cells in a dose-dependent manner. The LPS treatment upregulated mRNA abundance of tumor necrosis factor $\alpha$ (TNFA), interleukin-6 (IL6), and interleukin-1B (IL1B), whereas inhibition of histone deacetylase with TSA dampened this effect. More importantly, SB had clear dose-dependent effects on the inflammatory response by preventing upregulation of TNFA, IL6, and IL1B. Furthermore, pretreatment with TSA or SB attenuated the downregulation of histone $\mathrm{H} 3$ acetylation protein abundance induced by LPS. The greater ratio of $\mathrm{p}-\mathrm{I} \kappa \mathrm{B}$ $\alpha / \mathrm{I} \kappa \mathrm{B} \alpha$ and $\mathrm{p}-\mathrm{p} 65 / \mathrm{p} 65$ protein abundance and the increase in nuclear localization of NF- $\kappa \mathrm{B}$ p65 protein in response to LPS were attenuated by pretreatment with SB. Overall, the data indicated that exogenous SB
\end{abstract}

Received January 11, 2020.

Accepted April 22, 2020.

*Corresponding author: xuchuang7175@163.com alleviates mammary cell pro-inflammatory responses partly through post-translational mechanisms that diminish NF- $\kappa \mathrm{B}$ signaling. Thus, the cytoprotective effect of SB against an inflammatory challenge might represent a preventive tool to help the mammary gland against pathogens such as those causing mastitis.

Key words: butyrate, inflammation, mastitis, NF- $\kappa B$ pathway

\section{INTRODUCTION}

Mastitis is a widespread infectious disease in dairy herds worldwide (Yang et al., 2018). This disease is characterized by an inflammatory response in the mammary gland, resulting in reduced milk yield and quality (Wilson et al., 1997). Issues such as high cost of treatment and widespread epidemics not only have an economic impact but seriously affect the welfare and health of cows (Melchior et al., 2006; Viguier et al., 2009). Bovine mammary epithelial cells (BMEC) are not only essential for milk component synthesis but are also a major line of defense against the invasion of pathogens (Swanson et al., 2009). Both exogenous LPS from intramammary Escherichia coli and diet-induced endogenous LPS release from the rumen are considered to be major causative factors inducing BMEC inflammation (Fox, 2009).

Toll-like receptor 4 (TLR4) is an important patternrecognition receptor that plays a crucial role in the innate immune system, which can be activated by LPS (Mukherjee et al., 2016). Upon activation by LPS, TLR4 stimulates downstream signaling pathways and triggers the production of inflammatory cytokines (Günther et al., 2017; Wang et al., 2018). Nuclear factor-kappa $\mathrm{B}(\mathrm{NF}-\kappa \mathrm{B})$, which acts as a key inflammation regulator during bovine mastitis, is a downstream signaling

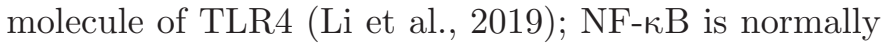
maintained in an inactive form by sequestration in the cytoplasm through interaction with inhibitor of $\kappa \mathrm{B} \alpha$ 
$(\mathrm{I} \kappa \mathrm{B} \alpha)$. A variety of extracellular stimuli lead to the rapid phosphorylation, ubiquitination, and ultimately proteolytic degradation of $\mathrm{I} \kappa \mathrm{B} \alpha$, which frees NF- $\kappa \mathrm{B}$ to translocate to the nucleus, where it regulates transcription of tumor necrosis factor $\alpha$ (TNFA), interleukin-6 (IL6), and interleukin-1B (IL1B; Karin and Ben-Neriah, 2000). In turn, these cytokines further aggravate the pathology and inflammatory responses involved in mastitis. Because inactivation of the TLR4-NF- $\mathrm{B}$ inflammation signaling pathway may protect BMEC against LPS-induced inflammation (Sun et al., 2019a), developing potential strategies to inhibit this pathway might lead to therapeutic approaches against mastitis.

Butyrate, one of the major short-chain fatty acids produced in the rumen, is a natural product of microbial fermentation of carbohydrate (Wong et al., 2006). Research with non-ruminant cell lines clearly underscored the anti-inflammatory, antioxidant and antiapoptotic properties of exogenous butyrate (Aguilar et al., 2014). Suppression of pro-inflammatory TNFA, IL6, and $I L 1 B$ is one of the main responses induced by butyrate (Bailón et al., 2010), but it also could encompass alterations in the degradation or phosphorylation of I $\kappa \mathrm{B} \alpha$ and dampening of NF- $\mathrm{BB}$ signaling (Machado et al., 2012; Lee et al., 2017). Recent studies with ruminal tissue (Dai et al., 2017) or bovine hepatocytes have underscored the anti-inflammatory potential of sodium butyrate (SB) at the transcriptional and post-translational level; for instance, SB inhibited histone deacetylase (HDAC) to control both abundance of pro-inflammatory cytokines

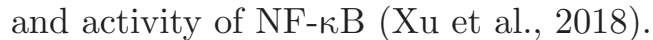

On the basis of available data, we hypothesized that SB might also protect against inflammatory responses induced by LPS in BMEC. Thus, the main objective of this study was to investigate the anti-inflammatory role of SB on BMEC by evaluating transcriptional and post-translational responses in vitro.

\section{MATERIALS AND METHODS}

\section{Cell Culture and Treatment}

The MAC-T cells were cultured in Dulbecco's modified Eagle medium, nutrient mixture F-12 (DMEM/F-12, Thermo Fisher Scientific, Grand Island, NY) containing $10 \%$ (vol/vol) fetal bovine serum (Thermo Fisher Scientific), $1 \%$ (vol/vol) antibiotic-antimycotic mix (penicillin $100 \mathrm{U} / \mathrm{mL}$, streptomycin $100 \mu \mathrm{g} / \mathrm{mL}$, and amphotericin B $0.25 \mu \mathrm{g} / \mathrm{mL}$; Hyclone, Logan, UT) at $37^{\circ} \mathrm{C}$ in a humidified atmosphere of $5 \% \mathrm{CO}_{2}$. The medium was changed every $24 \mathrm{~h}$. The SB (303410; SigmaAldrich, St. Louis, MO) was dissolved in distilled $\mathrm{H}_{2} \mathrm{O}$, and trichostatin A (TSA) (647925; Sigma-Aldrich) was dissolved in ethanol. Cells were pretreated with SB (0.1,
$0.25,0.5,1,2$, or $5 \mathrm{mM}$ ) for $18 \mathrm{~h}$, and then treated with 1 or $20 \mu \mathrm{g} / \mathrm{mL}$ LPS for $6 \mathrm{~h}$ in DMEM/F-12 medium without serum (to avoid fetal bovine serum affecting pro-inflammatory cytokine transcript abundance). Furthermore, cells were pretreated with TSA (6.25, $12.5,25$, or $50 \mathrm{n} M$ ) or ethanol $[0.1 \%$ ( $\mathrm{vol} / \mathrm{vol}$ ), vehicle control, Veh] in amounts equal to that present in TSA cultures for $18 \mathrm{~h}$, and then treated with $1 \mu \mathrm{g} / \mathrm{mL}$ LPS for $6 \mathrm{~h}$ in DMEM/F-12 medium without serum.

\section{Cell Viability}

Cell viability was measured using the Cell Counting Kit-8 (Dojindo, Kumamoto, Japan) according to manufacturer's instructions. The Cell Counting Kit-8 contains tetrazolium salt 2-(2-methoxy-4-nitrophenyl)3-(4-nitrophenyl)-5-(2,4-disulfophenyl)-2H-tetrazolium monosodium salt (WST-8) and the intermediate electron carrier 1-methoxy-5-methylphenazinium methyl sulfate (mPMS). Adjacent to metabolically active cells, the pink WST-8 is reduced extracellularly to a yellow reaction product called formazan. Its formation can be quantified photometrically, with the amount of formazan generated being directly proportional to metabolic activity - hence, the number of living cells in a given biological sample. The MAC-T cells $\left(1 \times 10^{5}\right.$ cells $\left./ \mathrm{mL}\right)$ were plated in 96 -well plates at $37^{\circ} \mathrm{C}$ for $4 \mathrm{~h}$. Cells were subsequently treated with $0.1,0.25,0.5,1,2$, or $5 \mathrm{~m} M$ SB for $18 \mathrm{~h}$, followed by a challenge with 1 or $20 \mu \mathrm{g} /$ $\mathrm{mL}$ LPS for $6 \mathrm{~h}$. After treatment, cells were incubated with $10 \mu \mathrm{L}$ of Cell Counting Kit- 8 solution at $37^{\circ} \mathrm{C}$ for $2 \mathrm{~h}$. The absorbance was measured at $450 \mathrm{~nm}$ with a microplate reader (Thermo Fisher Scientific). Cell viability was calculated as percentage relative to control cells, exposed to neither SB nor LPS.

\section{Measurement of Cell Apoptosis}

Cell apoptosis was determined according to a previous study (Sun et al., 2019b). After incubation with SB or LPS as indicated, cells were washed twice with PBS. Cell apoptosis was detected using an annexin V-FITC apoptosis detection kit (BD PharMingen, San Jose, CA) and analyzed by flow cytometry (Becton Dickinson, San Jose, CA). Apoptotic cells were expressed as percentage of the total cells.

\section{Immunofluorescence Staining}

Immunofluorescence staining was performed as described by $\mathrm{Xu}$ et al. (2018). The MAC-T cells were seeded in laser confocal Petri dishes (Corning Life Science, Lowell, MA) and incubated with SB or LPS as indicated. Cells were washed 3 times with PBS and 
fixed in $10 \%$ formaldehyde neutral buffer solution for 30 min at room temperature. After washing 3 times with PBS, antigen retrieval was performed using EDTA-Na at $95^{\circ} \mathrm{C}$ for $5 \mathrm{~min}$. Cells were then permeabilized with 0.1\% Triton X-100 (T9284; Sigma-Aldrich) for $10 \mathrm{~min}$, followed by washing 3 times with PBS. Subsequently, cells were incubated with primary antibody for NF- $\kappa \mathrm{B}$ p65 (sc-8008; Santa Cruz Biotechnology, Santa Cruz, $\mathrm{CA} ; 1: 50)$ at $4^{\circ} \mathrm{C}$ overnight, followed by washing 3 times with PBS. Cells were incubated with goat anti-mouse IgG conjugated with cy3 (A0521; Beyotime Institute of Biotechnology, Shanghai, China), washed 3 times with PBS, and stained with 4',6-diamidino-2-phenylindole (DAPI , $1 \mu \mathrm{g} / \mathrm{mL}$; D8417, Sigma-Aldrich) for $10 \mathrm{~min}$. Lastly, cells were visualized with a confocal laser microscope (TCS SP5, Leica Microsystems, Wetzlar, Germany), and images were taken under an Olympus (Tokyo, Japan) FLUOVIEW FV1000 microscope.

\section{Total RNA Extraction and Quantitative Reverse-Transcription PCR}

We performed RNA extraction using RNAiso Plus (Takara Biotechnology Co. Ltd., Dalian, China) following the supplier's protocols. Then, a K5500 Micro-Spectrophotometer (Beijing Kaiao Technology Development Ltd., Beijing, China) was used to measure RNA purity and concentration, with RNA quality measured via electrophoresis (1\% agarose gels).

In our study, the optical density (OD)260/OD280 ratio of the total RNA was determined to be 1.9 , and the intensity of the $28 \mathrm{~S}$ ribosomal RNA band was approximately twice the intensity of the $18 \mathrm{~S}$ ribosomal RNA band in total RNA samples, indicating that total RNA was of high quality. One $\mu \mathrm{g}$ total RNA was reversetranscribed into cDNA using a reverse transcription kit (RR047A, Takara Biotechnology Co. Ltd.) according to manufacturer's instructions. The quantitative reversetranscription PCR assays were performed as described by Zhu et al. (2019) using SYBR green plus reagent kit (Roche, Basel, Switzerland) with the 7500 RealTime PCR System (Applied Biosystems, Waltham, MA). Primer sets are listed in Supplemental Table S1 (https://doi.org/10.3168/jds.2020-18189). Ubiquitin B and GAPDH, already known to be suitable for BMEC (Griesbeck-Zilch et al., 2008), were used to normalize target gene abundance, followed by calculation of abundance using the $2^{-\Delta \Delta \mathrm{CT}}$ method. All reactions were run in triplicate.

\section{Protein Extraction and Western Blotting}

Cells were washed twice with $4^{\circ} \mathrm{C}$ PBS and extracted using a commercial protein extraction kit (C510003;
Sangon Biotech Co. Ltd., Shanghai, China) following the supplier's protocols. The BCA protein assays (P1511; Applygen Technologies, Beijing, China) were performed to measure protein concentration. Western blotting was performed as described previously (Sun et al., 2019b). Briefly, equal amounts of protein $(30 \mu \mathrm{g})$ were separated on an 8 to $15 \%$ Tris-glycine gel and electrotransferred onto $0.45 \mu \mathrm{m}$ polyvinylidene difluoride (PVDF) membranes. The PVDF membranes were blocked with $3 \%$ BSA in Tris-buffered saline $(50 \mathrm{mM}$ Tris, $\mathrm{pH}$ 7.6, $150 \mathrm{mM} \mathrm{NaCl}$, and $0.1 \%$ Tween 20 ) for $4 \mathrm{~h}$ at room temperature. Membranes were then incubated with antibodies against phosphorylatd-I $\kappa \mathrm{B} \alpha(\mathrm{p}-\mathrm{I} \kappa \mathrm{B} \alpha$; sc-271980, Santa Cruz Biotechnology; 1:5,000), I $\mathrm{B} \alpha$ (sc-166588, Santa Cruz Biotechnology; 1:1,000), NFкB p65 (sc-8008, Santa Cruz Biotechnology; 1:1,000),

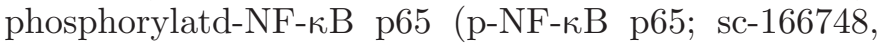
Santa Cruz Biotechnology; 1:1,000), acetyl-H3 (8173, Cell Signaling Technology, Danvers, MA; 1:1,000), histone H3 (4499, Cell Signaling Technology; 1:1,000), and GAPDH (ab8245, Abcam, Cambridge, MA; 1:5,000) overnight at $4^{\circ} \mathrm{C}$, followed by incubation with horseradish peroxidase-conjugated anti-mouse or anti-rabbit antibody (Boster, Wuhan, China) for $45 \mathrm{~min}$ at room temperature. Specific bands were visualized with an enhanced chemiluminescence solution detection kit (ECL, Millipore, Bedford, MA). The intensity of each band was quantified using Image-Pro Plus 6.0 software (Media Cybernetics Inc., Rockville, MD).

\section{Statistical Analysis}

Each cell culture treatment was performed in triplicate, and each of the determinations were performed 3 times for each treatment. Data were analyzed using GraphPad Prism 5 (GraphPad InStat Software, San Diego, CA) and were tested for normality. Comparisons among groups were made with one-way ANOVA followed by Bonferroni correction. The results are expressed as the mean and standard error of the mean (mean $\pm \mathrm{SEM}$ ). A $P<0.05$ was considered statistically significant.

\section{RESULTS}

\section{Effect of SB Supplementation on Cell Viability}

Compared with the control, $1 \mu \mathrm{g} / \mathrm{mL}$ LPS did not change MAC-T cell viability (Figure 1). However, compared with the control, $20 \mu \mathrm{g} / \mathrm{mL}$ LPS decreased MACT cell viability $(P=0.0212$, Figure 1$)$. Furthermore, compared with LPS cultures, viability was not affected by pretreatment with SB 0.1 to $5 \mathrm{~m} M$ plus challenge with LPS (Figure 1). 


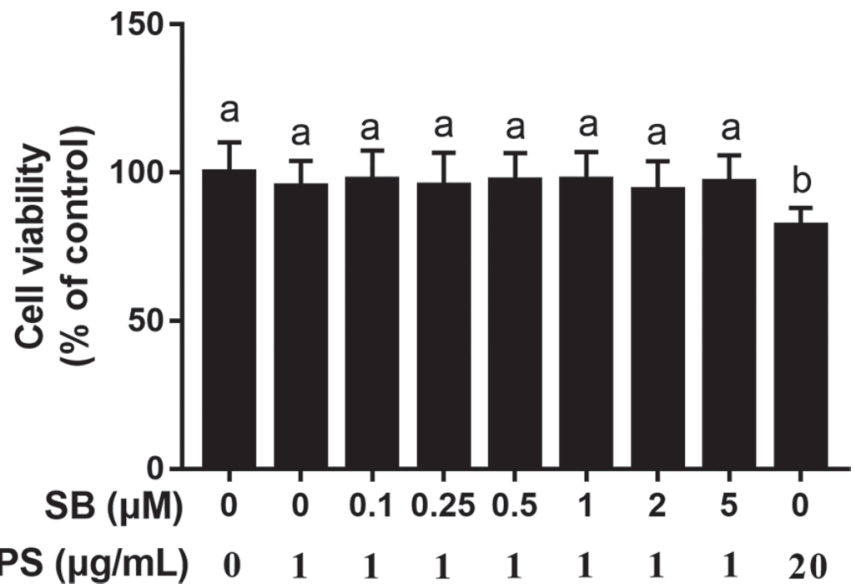

Figure 1. Effects of sodium butyrate (SB) on cell viability. Bovine mammary epithelial cells (MAC-T) were treated with 1 or $20 \mu \mathrm{g} / \mathrm{mL}$ LPS for $6 \mathrm{~h}$; with different concentrations of SB $(0.1,0.25,0.5,1,2$, or $5 \mathrm{~m} M)$ for $18 \mathrm{~h}$; or with different concentrations of SB $(0.1,0.25$, $0.5,1,2$, or $5 \mathrm{mM}$ ) for $18 \mathrm{~h}$, followed by a challenge with $1 \mu \mathrm{g} / \mathrm{mL}$ LPS for an additional $6 \mathrm{~h}$. Cell viability was determined using the Cell Counting Kit-8 assay (Dojindo, Kumamoto, Japan). Data from the control group were used to normalize the data of each treatment group. Comparisons among groups were calculated using a one-way ANOVA with subsequent Bonferroni correction. Data presented are mean \pm SEM. Different lowercase letters in the bar chart indicate significant differences $(P<0.05)$.

\section{SB Pretreatment Attenuated LPS-Induced Apoptosis}

Treatment with LPS sharply increased $(P=0.0002)$ cell apoptosis compared with the control group. However, compared with LPS cultures, pretreatment with $0.25(P=0.0419), 0.5(P=0.0068), 1 \quad(P=0.0058), 2$ $(P=0.0052)$, or $5(P=0.0007) \mathrm{m} M \mathrm{SB}$ decreased cell apoptosis (Figure 2).

\section{SB Pretreatment Attenuated LPS-Induced Cytokine Production}

Compared with the control cultures, LPS treatment upregulated mRNA abundance of TNFA $(P<0.0001)$, IL6 $(P<0.0001)$, and $I L 1 B(P<0.0001$; Figure $3 \mathrm{~A}-\mathrm{C})$. Whereas pretreatment with $6.25,12.5,25$, or $50 \mathrm{n} M$ of the HDAC inhibitor TSA attenuated the upregulation of TNFA $(P=0.0385, P=0.0209, P=0.0005$, or $P$ $=0.0003$, respectively $), I L 6(P=0.0421, P=0.0122$, $P=0.0002$, or $P<0.0001)$, and $I L 1 B(P=0.0378$, $P=0.0016, P<0.0001$, or $P<0.0001$ ) induced by LPS (Figure $3 \mathrm{~A}-\mathrm{C}$ ), pretreatment with Veh did not affect mRNA abundance of TNFA, IL6, or IL1B (Figure $4 \mathrm{~A}$ and B). Similarly, pretreatment with 0.1, 0.25, 0.5, 1,2 , or $5 \mathrm{~m} M$ SB markedly attenuated upregulation of TNFA $(P=0.0391, P=0.0316, P=0.0007, P=$ $0.0002, P<0.0001$, or $P<0.0001)$, IL6 $(P=0.0275$, $P=0.0054, P<0.0001, P<0.0001, P<0.0001$, or
$P<0.0001)$, and $I L 1 B(P=0.0427, P=0.0267, P=$ $0.0004, P<0.0001, P<0.0001$, or $P<0.0001)$ induced by LPS (Figure 3D-F).

\section{SB Pretreatment Attenuated LPS-Induced Reduction of Histone $\mathrm{H} 3$ Acetylation}

Compared with the control group, treatment with LPS reduced histone $\mathrm{H} 3$ acetylation $(P=0.0083$, Figure $4 \mathrm{~A}$ and $\mathrm{B})$. However, compared with the control group, treatment with Veh increased histone $\mathrm{H} 3$ acetylation $(P$ $=0.0247$, Figure $4 \mathrm{~A}$ and B). Compared with the LPStreated group, pretreatment with HDAC inhibitor TSA increased histone $\mathrm{H} 3$ acetylation $(P<0.0001$, Figure $4 \mathrm{~A}$ and $\mathrm{B})$, and pretreatment with Veh did not affect the histone $\mathrm{H} 3$ acetylation $(P=0.6877$, Figure $4 \mathrm{~A}$ and B). Similar to TSA, compared with the LPS-treated group, pretreatment with SB also increased histone $\mathrm{H} 3$ acetylation $(P=0.0079$, Figure $4 \mathrm{C}$ and $\mathrm{D})$.

\section{SB Pretreatment Downregulated the LPS-Activated NF-KB Signaling Pathway}

Compared with the control group, LPS treatment increased the ratio of $\mathrm{p}-\mathrm{I} \kappa \mathrm{B} \alpha$ to $\mathrm{I} \kappa \mathrm{B} \alpha(P=0.0050$, Figure $5 \mathrm{~A}$ and $\mathrm{B}$ ). In contrast, compared with the LPS-

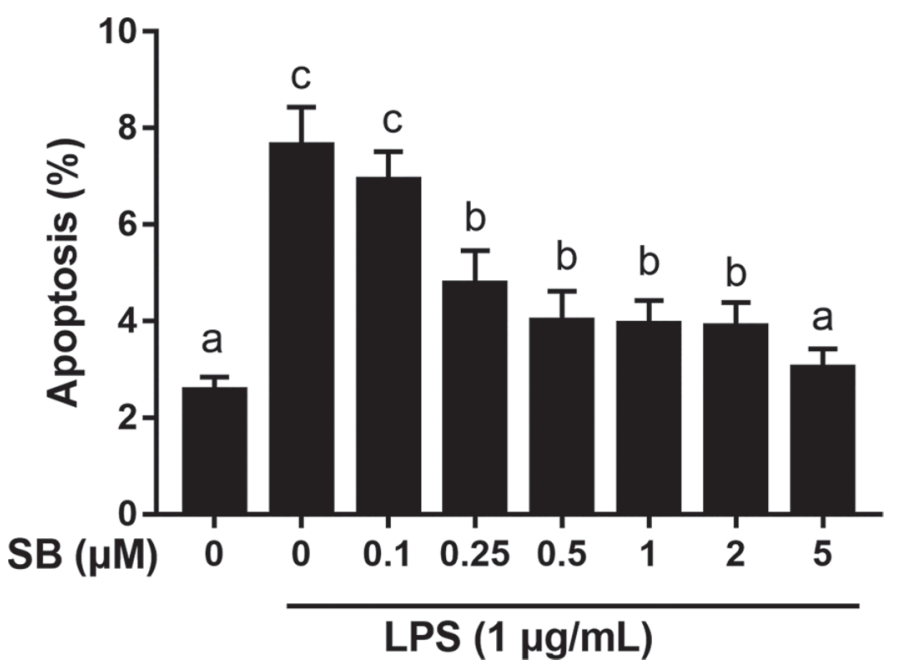

Figure 2. Effects of sodium butyrate (SB) on apoptosis of bovine mammary epithelial (MAC-T) cells. Cells were treated with $1 \mu \mathrm{g} / \mathrm{mL}$ LPS for $6 \mathrm{~h}$; with different concentrations of SB $(0.1,0.25,0.5,1,2$, or $5 \mathrm{mM}$ ) for $18 \mathrm{~h}$; or with different concentrations of SB $(0.1,0.25,0.5$, 1,2 , or $5 \mathrm{mM}$ ) for $18 \mathrm{~h}$, followed by a challenge with $1 \mu \mathrm{g} / \mathrm{mL}$ LPS for an additional $6 \mathrm{~h}$. The percentage of apoptotic cells was determined by flow cytometry. Data from the control group were used to normalize the data of each treatment group. Comparisons among groups were calculated using a one-way ANOVA with subsequent Bonferroni correction. Data presented are mean \pm SEM. Different lowercase letters in the bar chart indicate significant differences $(P<0.05)$. 

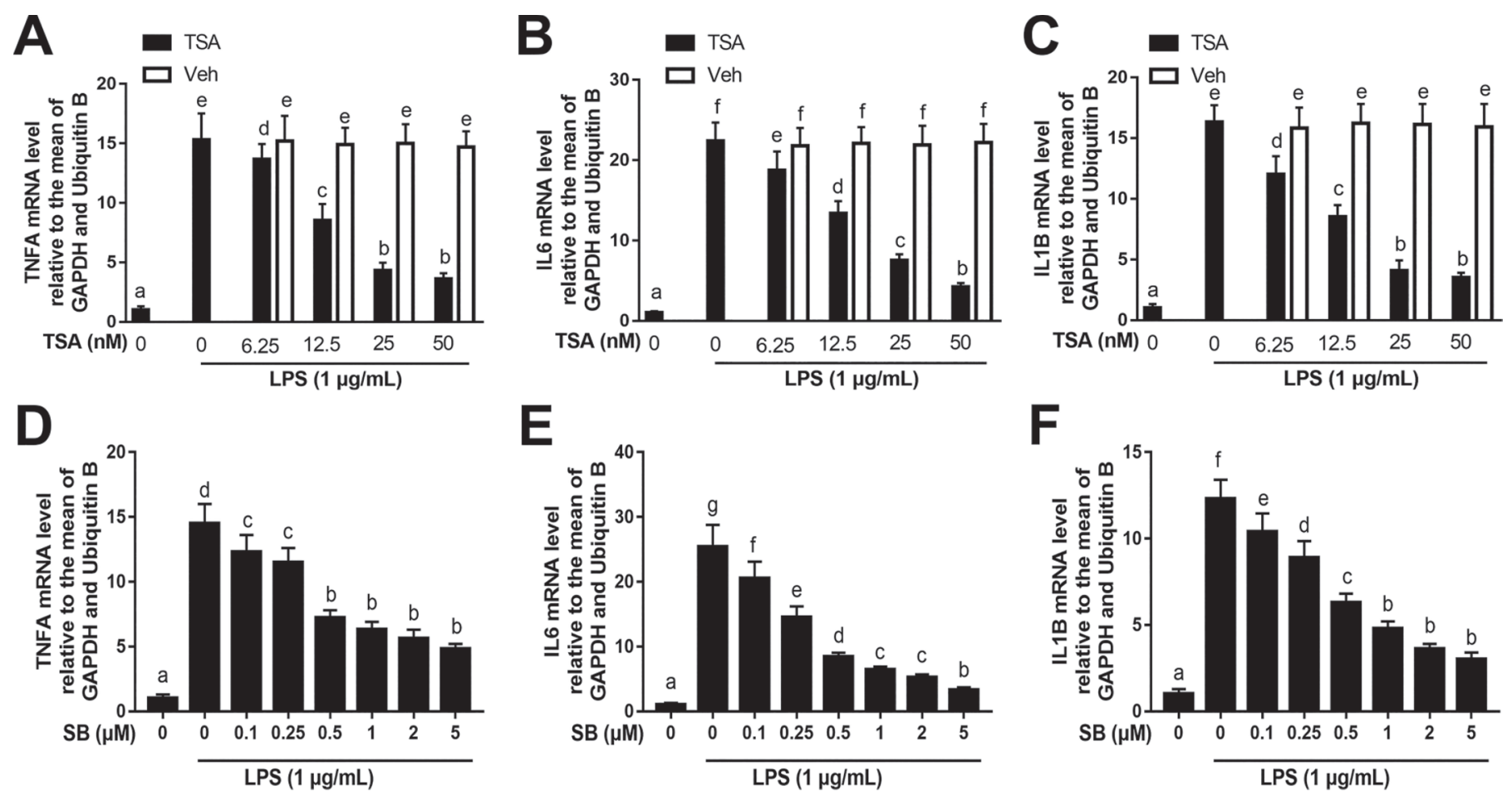

Figure 3. Effects of sodium butyrate (SB) on cytokine production. Bovine mammary epithelial cells $(\mathrm{MAC}-\mathrm{T})$ were treated with $1 \mu \mathrm{g} / \mathrm{mL}$ LPS for $6 \mathrm{~h}$; with different concentrations of trichostatin A (TSA; 6.25, 12.5, 25, or $50 \mathrm{nM}$ ) for $18 \mathrm{~h}$, followed by a challenge with $1 \mu \mathrm{g} / \mathrm{mL}$ LPS for an additional $6 \mathrm{~h}$; with amounts of solvent $[0.1 \%$ (vol/vol) ethanol, vehicle control (Veh)] equal to that present in TSA cultures for $18 \mathrm{~h}$, followed by a challenge with $1 \mu \mathrm{g} / \mathrm{mL}$ LPS for an additional $6 \mathrm{~h}$; or with different concentrations of SB $(0.1,0.25,0.5,1,2$, or $5 \mathrm{~m} M)$ for $18 \mathrm{~h}$, followed by a challenge with $1 \mu \mathrm{g} / \mathrm{mL}$ LPS for an additional $6 \mathrm{~h}$. (A) Relative mRNA expression level of TNFA. (B) Relative mRNA expression level of $I L 6$. (C) Relative mRNA expression level of $I L 1 B$. (D) Relative mRNA expression level of TNFA. (E) Relative mRNA expression level of IL6. (F) Relative mRNA expression level of $I L 1 B$. Data from the control group were used to normalize the data of each treatment group. Comparisons among groups were calculated using a one-way ANOVA with subsequent Bonferroni correction. Data presented are mean \pm SEM. Different lowercase letters in bar charts indicate significant differences $(P<0.05)$.

treated group, pretreatment with $\mathrm{SB}$ reduced the ratio of $\mathrm{p}-\mathrm{I} \kappa \mathrm{B} \alpha$ to $\mathrm{I} \kappa \mathrm{B} \alpha(P=0.0052$, Figure $5 \mathrm{~A}$ and $\mathrm{B})$. Similarly, LPS treatment also increased the ratio of p-p65 to p65 $(P=0.0017)$, whereas pretreatment with $\mathrm{SB}$ attenuated the upregulation of the ratio of p-p65 to p65 induced by LPS $(P=0.0098$, Figure $5 \mathrm{~A}$ and $\mathrm{C})$. Consistent with the alterations in the ratio of p-p65 to p65, immunofluorescence staining results revealed that, compared with the control group, LPS treatment increased NF- $\kappa$ B p65 translocation to the nucleus. However, compared with the LPS-treated group, NF-kB p65 translocation to the nucleus was greatly decreased in the group treated with SB plus LPS (Figure 6).

\section{DISCUSSION}

The BMEC play an essential role in the host response by alerting the immune system to invasion of pathogens; hence, they are a major line of defense of the mammary gland (Rainard and Riollet, 2003). Dysregulation of inflammatory responses has a critical role in the progression of bovine mastitis. Cytokines act as intercellular chemical messengers involved in the regulation of immune homeostasis and inflammatory responses against different infections (Okada et al., 1999). Among the cytokines, TNFA, IL6, and IL1B are considered pro-inflammatory, with various studies reporting upregulation of TNFA, IL6, and ILIB mRNA abundance during coliform mastitis in the transition period (Sordillo and Peel, 1992; Shuster et al., 1993). In vitro, the abundance of these cytokines in BMEC exposed to LPS also increases (Wang et al., 2016). Thus, reduction of pro-inflammatory cytokine production may be an effective strategy for treating mastitis. The downregulation of mRNA abundance of TNFA, IL6, and IL1B in LPS-challenged cells that were pretreated with SB underscored the positive effect of SB on the inflammatory responses of BMEC. These data agree with recent data in ruminal epithelium and bovine hepatocytes (Dai et al., 2017; Xu et al., 2018). In the absence of an inflammatory challenge, the viability of mouse mammary epithelial cells was not affected by 0.1 to $2 \mathrm{~m} M$ SB treatment for $18 \mathrm{~h}$ (Wang et al., 2017). Thus, together, the available data suggest that 

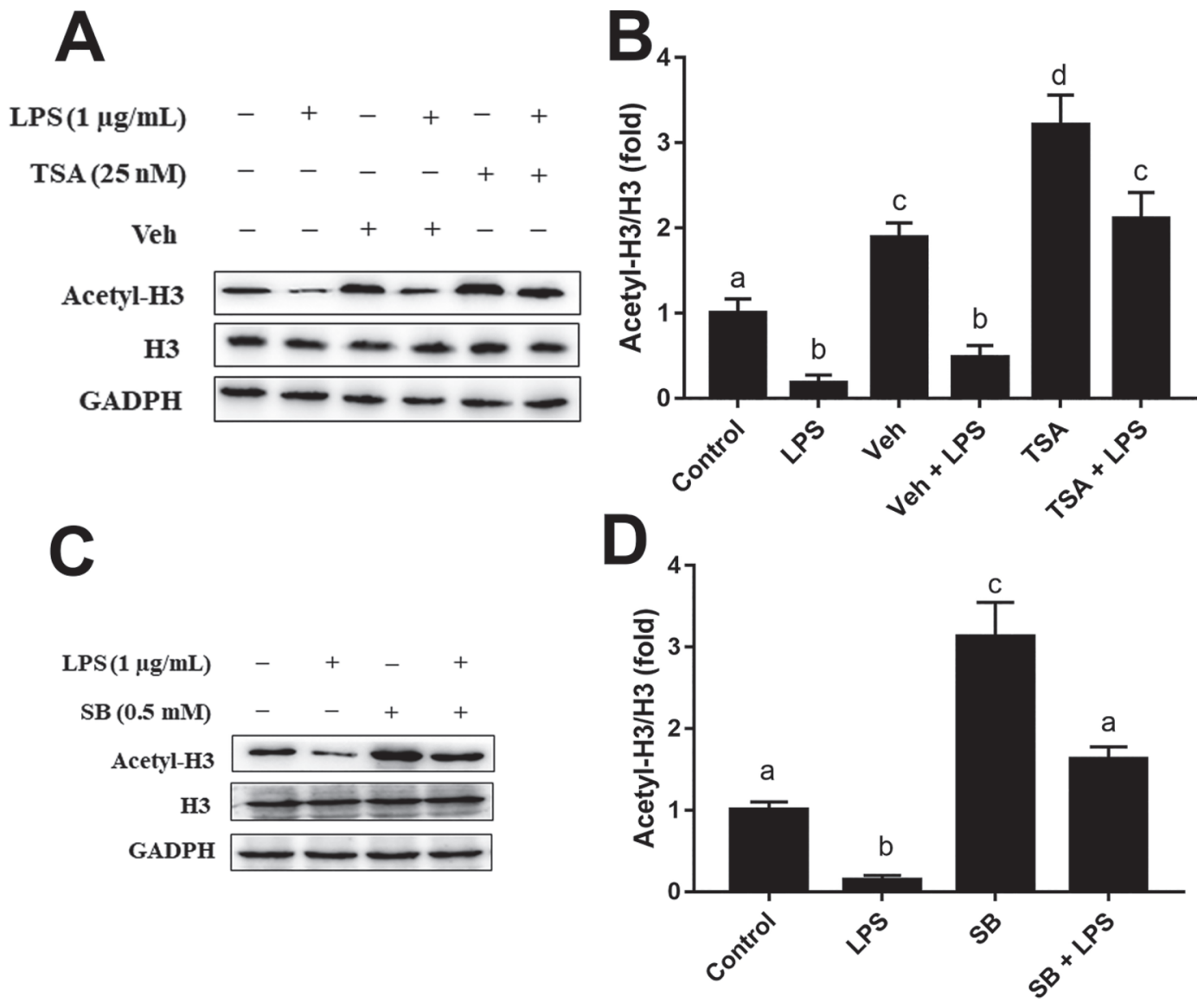

Figure 4. Effects of sodium butyrate (SB) on histone H3 acetylation. Bovine mammary epithelial cells (MAC-T) were treated with $1 \mu \mathrm{g} / \mathrm{mL}$ LPS for $6 \mathrm{~h}$; with $0.5 \mathrm{~m} M$ SB for $18 \mathrm{~h}$; with $25 \mathrm{n} M$ trichostatin A (TSA) for $18 \mathrm{~h}$; with an amount of solvent [0.1\% (vol/vol) ethanol, vehicle control (Veh)] equal to that present in TSA cultures for $18 \mathrm{~h}$; with $0.5 \mathrm{mM}$ SB for $18 \mathrm{~h}$, followed by a challenge with $1 \mu \mathrm{g} / \mathrm{mL}$ LPS for an additional $6 \mathrm{~h}$; with $25 \mathrm{n} M$ TSA for $18 \mathrm{~h}$, followed by a challenge with $1 \mu \mathrm{g} / \mathrm{mL}$ LPS for an additional $6 \mathrm{~h}$; or with an amount of Veh equal to that present in TSA cultures for $18 \mathrm{~h}$, followed by a challenge with $1 \mu \mathrm{g} / \mathrm{mL}$ LPS for an additional $6 \mathrm{~h}$. (A) Western blot analysis of acetylated histone H3 and histone H3. (B) Relative protein expression levels of acetylated histone H3 and histone H3. (C) Western blot analysis of acetylated histone H3 and histone H3. (D) Relative protein expression levels of acetylated histone H3 and histone H3. Data from the control group were used to normalize the data of each treatment group. Comparisons among groups were calculated using a one-way ANOVA with subsequent Bonferroni correction. Data presented are mean \pm SEM. Different lowercase letters in bar charts indicate significant differences $(P<0.05)$.

the anti-inflammatory effect of SB is not due to differences in cell numbers before LPS challenge. As such, an enhanced supply of SB might exert a preventive effect against inflammation in ruminants.

The protein NF- $\kappa \mathrm{B}$ is a nuclear transcription factor that plays a crucial role in the innate immune system. Activation of NF- $\kappa \mathrm{B}$ is involved in the inflammatory processes associated with development of mastitis (Gong et al., 2018). Upon stimulation of cells by a variety of chemical and mechanical signals that lead to phosphorylation and degradation of $\mathrm{I} \kappa \mathrm{B} \alpha, \mathrm{NF}-\kappa \mathrm{B}$ is phosphorylated and translocated into the nucleus, triggering transcription of inflammatory cytokines (Niederberger and Geisslinger, 2008). Thus, inhibition of NF- $\kappa \mathrm{B}$ activation has attracted attention as a therapeutic approach for intervention during immune and inflammatory events (Calzado et al., 2007).
At least in non-ruminants, the anti-inflammatory response potential of SB stems from its ability to prevent phosphorylation and degradation of I $\kappa \mathrm{B} \alpha$ (Usami et al., 2008). Compared with cultures challenged with LPS, downregulation of the phosphorylation of I $\kappa \mathrm{B} \alpha$ in cultures treated with SB and LPS suggested that pretreatment with $\mathrm{SB}$ was effective in attenuating the phosphorylation of $\mathrm{I} \kappa \mathrm{B} \alpha$ resulting from LPS challenge. Upon phosphorylation of I $\kappa \mathrm{B} \alpha$ in response to LPS, a concomitant increase in phosphorylated NF- $\kappa$ B p65 and production of pro-inflammatory cytokines has been reported (Lee et al., 2017), suggesting that preventing phosphorylation of I $\kappa \mathrm{B} \alpha$ might be an important goal. The fact that cultures treated with SB and LPS decreased phosphorylated NF- $\mathrm{B}$ p 65 movement into the nucleus is consistent with previous findings in bovine hepatocytes (Xu et al., 2018). Thus, the data suggest 


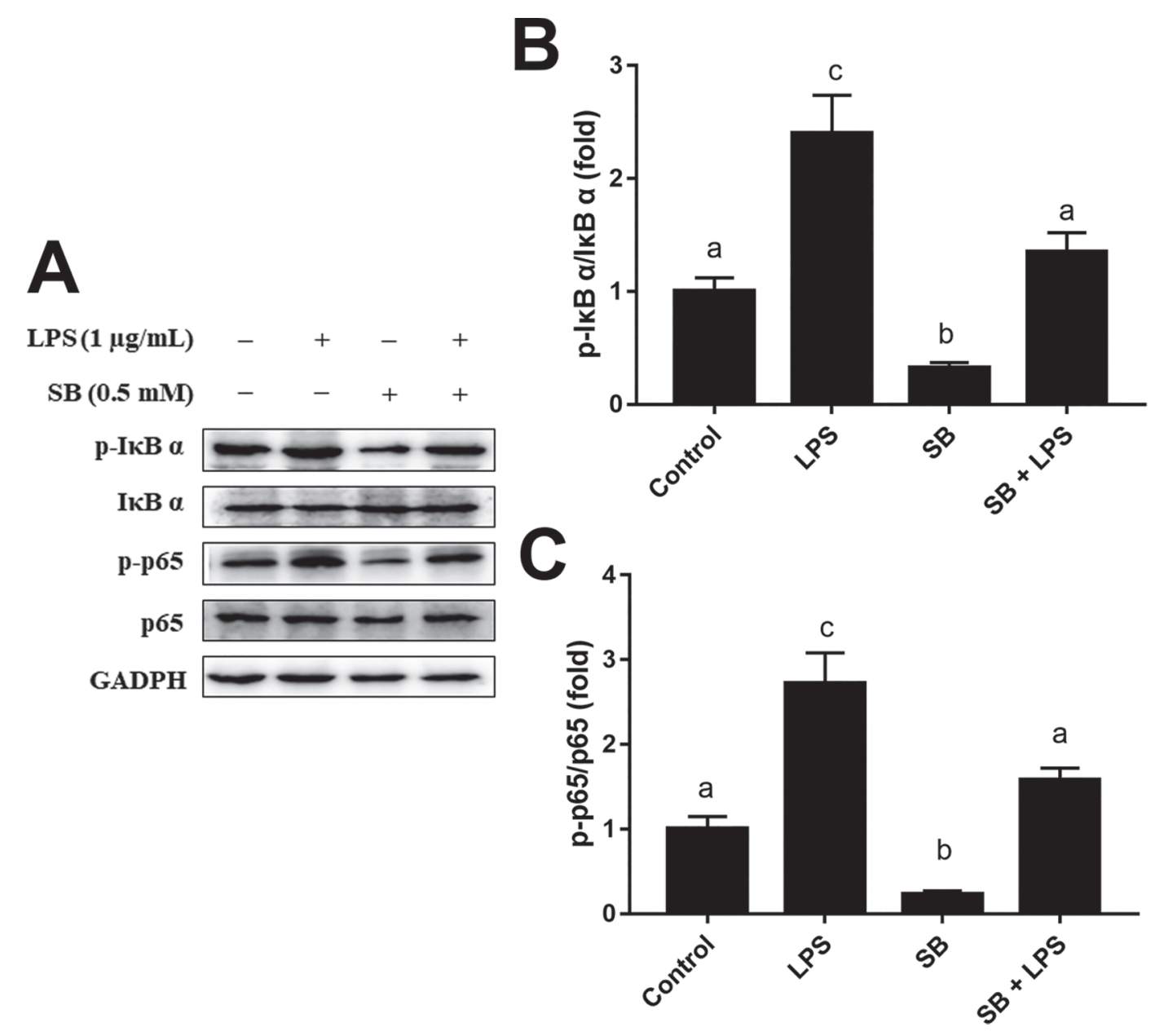

Figure 5. Effects of sodium butyrate (SB) on NF- $\kappa B$ signaling pathway. Bovine mammary epithelial cells (MAC-T) were treated with 1 $\mu \mathrm{g} / \mathrm{mL}$ LPS for $6 \mathrm{~h}$; with $0.5 \mathrm{~m} M \mathrm{SB}$ for $18 \mathrm{~h}$; or with $0.5 \mathrm{mM} \mathrm{SB}$ for $18 \mathrm{~h}$, followed by a challenge with $1 \mu \mathrm{g} / \mathrm{mL}$ LPS for an additional $6 \mathrm{~h}$.

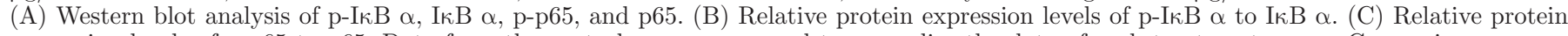
expression levels of p-p65 to p65. Data from the control group were used to normalize the data of each treatment group. Comparisons among groups were calculated using a one-way ANOVA with subsequent Bonferroni correction. Data presented are mean \pm SEM. Different lowercase letters in bar charts indicate significant differences $(P<0.05)$.

that SB pretreatment ameliorates LPS-induced activation of the NF- $\kappa \mathrm{B}$ pathway, which may help attenuate or modulate immune responses by BMEC.

The level of the inflammatory response is clearly dependent on the activation state of NF- $\mathrm{BB}$, which is tightly regulated by modification of histone acetylation status. By modifying histone acetylation, HDAC play a key role in the regulation of $\mathrm{NF}-\kappa \mathrm{B}$-dependent inflammation. In the clinical setting, HDAC inhibitors have already been used to treat inflammatory diseases including rheumatoid arthritis, asthma, and ischemiareperfusion injury in humans (Granger et al., 2008; Grabiec et al., 2010; Royce and Karagiannis, 2012). Although HDAC inhibitors have not been applied to the treatment of infectious diseases, previous studies have revealed that $\mathrm{SB}$ is an HDAC inhibitor, which could induce histone acetylation and reduce the NF- $\kappa \mathrm{B}$-dependent inflammatory response (Place et al., 2005; Wang et al., 2017). The fact that Silva et al. (2018) reported that pretreatment of MAC-T cells with SB increased histone $\mathrm{H} 3$ acetylation underscores the possibility that, during conditions when histone acetylation is increased, the NF- $\kappa \mathrm{B}$-dependent inflammatory response is inhibited. Along with the downregulation of phosphorylated NF- $\kappa$ B p65 and reduction of inflammatory cytokine transcription, the upregulation of histone acetylation in cultures with SB pretreatment followed by LPS stimulation support the role of SB as an HDAC inhibitor, leading to dampening of the inflammatory response. Taken together, the available data confirm that SB may also be effective in the prevention of inflammatory responses induced by LPS.

Despite the acknowledged limitations of the studyfor instance, protein abundance of the pro-inflammatory 
cytokines was not evaluated, and SB supplementation was performed before the inflammatory insult (LPS)the present study establishes a potential strategy for SB supplementation to prevent inflammatory responses in MAC-T cells. Based on the present data, it is expected that SB controls inflammation via regulation of mRNA abundance and phosphorylation of key proteins. Future research into BMEC and the bovine mammary gland are needed to better understand the mechanisms of action of SB against mammary inflammation.

The use of short-chain fatty acids as a feed additive continues to receive attention in the animal nutrition community. For instance, butyrate is known to enhance performance and benefit gut health in non-ruminants (Robles et al., 2013). In isolated goat mammary cells, Chang et al. (2018) reported that dietary SB supplementation reduced apoptosis induced by highconcentrate diet feeding, through the attenuating activation of NF- $\mathrm{BB}$ and CASP3. Although most butyrate is converted to BHB by the ruminal epithelium, and very little butyrate makes it past the liver, the reduced concentrations of LPS and proinflammatory cytokines reported in vivo, together with our data, indicate that an SB feed additive might be effective in preventing LPS-associated mastitis. Although attenuation of inflammation by SB may impair the sentinel function of the mammary gland and allow for infection to be established more easily, future research on the applicability of SB should determine the optimal dose that reduces inflammation without impairing the sentinel function of the mammary gland.

\section{CONCLUSIONS}

Enhanced supply of SB protects MAC-T cells against LPS-induced inflammation partly by decreasing mRNA abundance of TNFA, IL6, and IL1B. Downregulation of the phosphorylation of $\mathrm{I} \kappa \mathrm{B} \alpha$ and transport of phosphorylated NF- $\kappa B$ p65 into the nucleus by SB suggest that inactivation of the NF- $\kappa \mathrm{B}$ pathway is involved in the cytoprotective effect of SB. Furthermore, the antiinflammatory response functions of SB in MAC-T cells might be partly mediated by its upregulation of histone acetylation. Thus, control of the NF- $\kappa \mathrm{B}$ pathway and

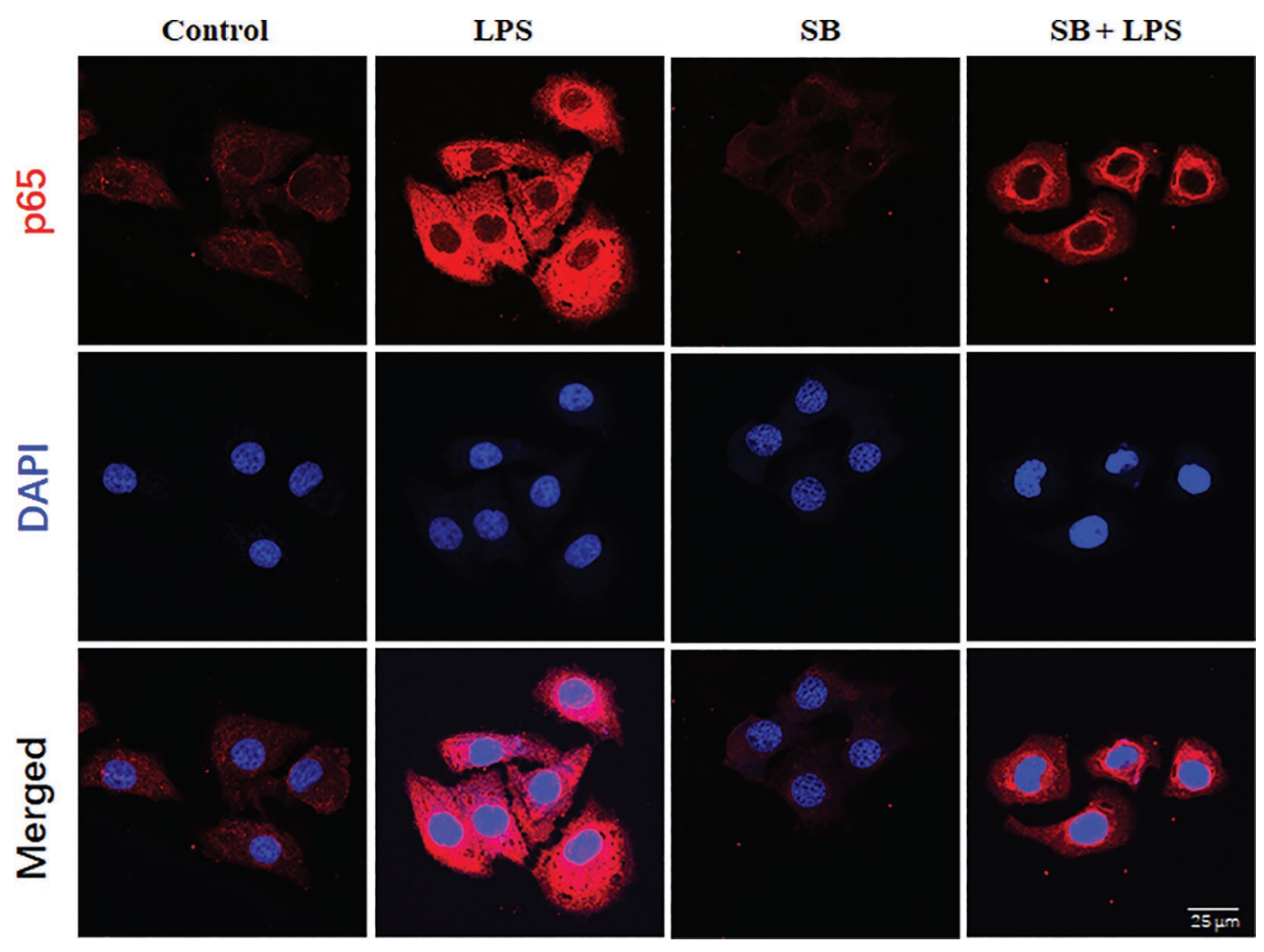

Figure 6. Effects of sodium butyrate (SB) on the location of NF- $\kappa$ B p65 protein. Bovine mammary epithelial cells (MAC-T) were treated with $1 \mu \mathrm{g} / \mathrm{mL}$ LPS for $6 \mathrm{~h}$; with $0.5 \mathrm{mM}$ SB for $18 \mathrm{~h}$; or with $0.5 \mathrm{~m} M \mathrm{SB}$ for $18 \mathrm{~h}$, followed by a challenge with $1 \mu \mathrm{g} / \mathrm{mL}$ LPS for an additional $6 \mathrm{~h}$. Afterward, immunofluorescence for NF- $\mathrm{BB}$ p65 (red) was performed, and the nuclear dye 4',6-diamidino-2-phenylindole (DAPI; blue) was used. Scale bar $=25 \mu \mathrm{m}$. 
downstream pro-inflammatory cytokine production constitute important mechanisms for SB action against inflammation.

\section{ACKNOWLEDGMENTS}

This work was supported by the Project funded by China Postdoctoral Science Function (Beijing, China; grant no. 2019M661316), the National Natural Science Foundation of China (Beijing, China; grant no. 31672622), the Heilongjiang Postdoctoral Science Foundation (Heilongjiang, China; grant no. LBHZ19090), and the Personnel Foundation in Heilongjiang Bayi Agricultural University (Daqing, China; grant no. XYB201909). XS and CX conceived the study; XS, SL, CJ, YT, ZC, HJ, QX, CZ, and CX carried out experiments and data analysis; XS, JJL, and CX interpreted the data. XS, JJL, and CX wrote the manuscript. All authors approved the final version. The authors declare that no conflicts of interest exist.

\section{REFERENCES}

Aguilar, E. C., A. J. Leonel, L. G. Teixeira, A. R. Silva, J. F. Silva, J. M. Pelaez, L. S. Capettini, V. S. Lemos, R. A. Santos, and J. I. Alvarez-Leite. 2014. Butyrate impairs atherogenesis by reducing plaque inflammation and vulnerability and decreasing NFkB activation. Nutr. Metab. Cardiovasc. Dis. 24:606-613. https://doi .org/10.1016/j.numecd.2014.01.002.

Bailón, E., M. Cueto-Sola, P. Utrilla, M. E. Rodríguez-Cabezas, N. Garrido-Mesa, A. Zarzuelo, J. Xaus, J. Gálvez, and M. Comalada. 2010. Butyrate in vitro immune-modulatory effects might be mediated through a proliferation-related induction of apoptosis. Immunobiology 215:863-873. https://doi.org/10.1016/j.imbio 2010.01.001.

Calzado, M. A., S. Bacher, and M. L. Schmitz. 2007. NF-kappaB inhibitors for the treatment of inflammatory diseases and cancer. Curr. Med. Chem. 14:367-376. https://doi.org/10.2174/ 092986707779941113.

Chang, G., J. Yan, N. Ma, X. Liu, H. Dai, M. S. Bilal, and X. Shen. 2018. Dietary sodium butyrate supplementation reduces highconcentrate diet feeding-induced apoptosis in mammary cells in dairy goats. J. Agric. Food Chem. 66:2101-2107. https://doi.org/ 10.1021/acs.jafc.7b05882.

Dai, H., X. Liu, J. Yan, Z. U. Aabdin, M. S. Bilal, and X. Shen. 2017. Sodium butyrate ameliorates high-concentrate diet-induced inflammation in the rumen epithelium of dairy goats. J. Agric. Food Chem. 65:596-604. https://doi.org/10.1021/acs.jafc.6b04447.

Fox, L. K. 2009. Prevalence, incidence and risk factors of heifer mastitis. Vet. Microbiol. 134:82-88. https://doi.org/10.1016/j.vetmic .2008.09.005

Gong, Q., Y. Li, H. Ma, W. Guo, X. Kan, D. Xu, J. Liu, and S. Fu. 2018. Peiminine protects against lipopolysaccharide-induced mastitis by inhibiting the AKT/NF- $\mathrm{BB}$, ERK1/2 and p38 signaling pathways. Int. J. Mol. Sci. 19:2637. https://doi.org/10.3390/ ijms19092637.

Grabiec, A. M., S. Krausz, W. de Jager, T. Burakowski, D. Groot, M. E. Sanders, B. J. Prakken, W. Maslinski, E. Eldering, P. P. Tak, and K. A. Reedquist. 2010. Histone deacetylase inhibitors suppress inflammatory activation of rheumatoid arthritis patient synovial macrophages and tissue. J. Immunol. 184:2718-2728. https://doi .org/10.4049/jimmunol.0901467.

Granger, A., I. Abdullah, F. Huebner, A. Stout, T. Wang, T. Huebner, J. A. Epstein, and P. J. Gruber. 2008. Histone deacetylase inhibition reduces myocardial ischemia-reperfusion injury in mice. FASEB J. 22:3549-3560. https://doi.org/10.1096/fj.08-108548.

Griesbeck-Zilch, B., H. H. Meyer, C. H. Kühn, M. Schwerin, and O. Wellnitz. 2008. Staphylococcus aureus and Escherichia coli cause deviating expression profiles of cytokines and lactoferrin messenger ribonucleic acid in mammary epithelial cells. J. Dairy Sci. 91:2215-2224. https://doi.org/10.3168/jds.2007-0752.

Günther, J., W. Petzl, H. Zerbe, H. J. Schuberth, and H. M. Seyfert. 2017. TLR ligands, but not modulators of histone modifiers, can induce the complex immune response pattern of endotoxin tolerance in mammary epithelial cells. Innate Immun. 23:155-164. https://doi.org/10.1177/1753425916681076.

Karin, M., and Y. Ben-Neriah. 2000. Phosphorylation meets ubiquitination: the control of NF-[kappa]B activity. Annu. Rev. Immunol. 18:621-663. https://doi.org/10.1146/annurev.immunol.18.1.621.

Lee, C., B. G. Kim, J. H. Kim, J. Chun, J. P. Im, and J. S. Kim. 2017. Sodium butyrate inhibits the NF-kappa B signaling pathway and histone deacetylation, and attenuates experimental colitis in an IL10 independent manner. Int. Immunopharmacol. 51:47-56. https:/ /doi.org/10.1016/j.intimp.2017.07.023.

Li, C., L. Li, K. Chen, Y. Wang, F. Yang, and G. Wang. 2019. UFL1 alleviates lipopolysaccharide-induced cell damage and inflammation via regulation of the TLR4/NF- $\kappa B$ pathway in bovine mammary epithelial cells. Oxid. Med. Cell. Longev. 2019:6505373. https://doi.org/10.1155/2019/6505373.

Machado, R. A., L. S. Constantino, C. D. Tomasi, H. A. Rojas, F. S. Vuolo, M. F. Vitto, P. A. Cesconetto, C. T. de Souza, C. Ritter, and F. Dal-Pizzol. 2012. Sodium butyrate decreases the activation of $\mathrm{NF}-\kappa \mathrm{B}$ reducing inflammation and oxidative damage in the kidney of rats subjected to contrast-induced nephropathy. Nephrol. Dial. Transplant. 27:3136-3140. https://doi.org/10.1093/ndt/ gfr807.

Melchior, M. B., H. Vaarkamp, and J. Fink-Gremmels. 2006. Biofilms: A role in recurrent mastitis infections? Vet. J. 171:398-407. https: //doi.org/10.1016/j.tvj1.2005.01.006.

Mukherjee, S., S. Karmakar, and S. P. Babu. 2016. TLR2 and TLR4 mediated host immune responses in major infectious diseases: A review. Braz. J. Infect. Dis. 20:193-204. https://doi.org/10.1016/ j.bjid.2015.10.011.

Niederberger, E., and G. Geisslinger. 2008. The IKK-NF-kappaB pathway: A source for novel molecular drug targets in pain therapy? FASEB J. 22:3432-3442. https://doi.org/10.1096/fj.08-109355.

Okada, H., H. Ohtsuka, S. Kon-Nai, R. Kirisawa, Y. Yokomizo, T. Yoshino, and T. J. Rosol. 1999. Effects of lipopolysaccharide on production of interleukin-1 and interleukin- 6 by bovine mammary epithelial cells in vitro. J. Vet. Med. Sci. 61:33-35. https://doi.org/ 10.1292/jvms.61.33.

Place, R. F., E. J. Noonan, and C. Giardina. 2005. HDAC inhibition prevents NF- $\kappa \mathrm{B}$ activation by suppressing proteasome activity: Down-regulation of proteasome subunit expression stabilizes

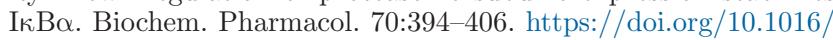
j.bcp.2005.04.030.

Rainard, P., and C. Riollet. 2003. Mobilization of neutrophils and defense of the bovine mammary gland. Reprod. Nutr. Dev. 43:439457. https://doi.org/10.1051/rnd:2003031.

Robles, R., A. B. Lozano, A. Sevilla, L. Márquez, W. Nuez-Ortín, and F. J. Moyano. 2013. Effect of partially protected butyrate used as feed additive on growth and intestinal metabolism in sea bream (Sparus aurata). Fish Physiol. Biochem. 39:1567-1580. https://doi .org/10.1007/s10695-013-9809-3.

Royce, S. G., and T. C. Karagiannis. 2012. Histone deacetylases and their role in asthma. J. Asthma 49:121-128. https://doi.org/10 .3109/02770903.2011.648298.

Shuster, D. E., M. E. Kehrli Jr., and M. G. Stevens. 1993. Cytokine production during endotoxin-induced mastitis in lactating dairy cows. Am. J. Vet. Res. 54:80-85.

Silva, L. G., B. S. Ferguson, A. S. Avila, and A. P. Faciola. 2018. Sodium propionate and sodium butyrate effects on histone deacetylase (HDAC) activity, histone acetylation, and inflammatory gene expression in bovine mammary epithelial cells. J. Anim. Sci 96:5244-5252. https://doi.org/10.1093/jas/sky373. 
Sordillo, L. M., and J. E. Peel. 1992. Effect of interferon-gamma on the production of tumor necrosis factor during acute Escherichia coli mastitis. J. Dairy Sci. 75:2119-2125. https://doi.org/10.3168/jds .S0022-0302(92)77971-5.

Sun, L., L. Chen, F. Wang, X. Zheng, C. Yuan, Q. Niu, Z. Li, L. Deng, B. Zheng, C. Li, and X. Zhou. 2019a. Exogenous hydrogen sulfide prevents lipopolysaccharide-induced inflammation by blocking the

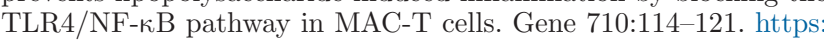
//doi.org/10.1016/j.gene.2019.05.033.

Sun, X., H. Jia, Q. Xu, C. Zhao, and C. Xu. 2019b. Lycopene alleviates $\mathrm{H}_{2} \mathrm{O}_{2}$-induced oxidative stress, inflammation and apoptosis in bovine mammary epithelial cells via the NFE2L2 signaling pathway. Food Funct. 10:6276-6285. https://doi.org/10.1039/C9FO01922G.

Swanson, K. M., K. Stelwagen, J. Dobson, H. V. Henderson, S. R. Davis, V. C. Farr, and K. Singh. 2009. Transcriptome profiling of Streptococcus uberis-induced mastitis reveals fundamental differences between immune gene expression in the mammary gland and in a primary cell culture model. J. Dairy Sci. 92:117-129. https:// doi.org/10.3168/jds.2008-1382.

Usami, M., K. Kishimoto, A. Ohata, M. Miyoshi, M. Aoyama, Y. Fueda, and J. Kotani. 2008. Butyrate and trichostatin A attenuate nuclear factor $\mathrm{\kappa B}$ activation and tumor necrosis factor $\alpha$ secretion and increase prostaglandin E2 secretion in human peripheral blood mononuclear cells. Nutr. Res. 28:321-328. https://doi.org/ 10.1016/j.nutres.2008.02.012.

Viguier, C., S. Arora, N. Gilmartin, K. Welbeck, and R. O'Kennedy. 2009. Mastitis detection: Current trends and future perspectives. Trends Biotechnol. 27:486-493. https://doi.org/10.1016/j.tibtech 2009.05.004.

Wang, J., C. Guo, Z. Wei, X. He, J. Kou, E. Zhou, Z. Yang, and Y. Fu. 2016. Morin suppresses inflammatory cytokine expression by downregulation of nuclear factor- $\kappa \mathrm{B}$ and mitogen-activated protein kinase (MAPK) signaling pathways in lipopolysaccharidestimulated primary bovine mammary epithelial cells. J. Dairy Sci. 99:3016-3022. https://doi.org/10.3168/jds.2015-10330.
Wang, J. J., Z. K. Wei, X. Zhang, Y. N. Wang, Y. H. Fu, and Z. T. Yang. 2017. Butyrate protects against disruption of the blood-milk barrier and moderates inflammatory responses in a model of mastitis induced by lipopolysaccharide. Br. J. Pharmacol. 174:38113822. https://doi.org/10.1111/bph.13976.

Wang, X., S. Feng, N. Ding, Y. He, C. Li, M. Li, X. Ding, H. Ding, J. Li, J. Wu, and Y. Li. 2018. Anti-inflammatory effects of berberine hydrochloride in an LPS-induced murine model of mastitis. Evid. Based Complement. Alternat. Med. 2018:5164314. https:// doi.org/10.1155/2018/5164314.

Wilson, D. J., R. N. Gonzalez, and H. H. Das. 1997. Bovine mastitis pathogens in New York and Pennsylvania: Prevalence and effects on somatic cell count and milk production. J. Dairy Sci. 80:25922598. https://doi.org/10.3168/jds.S0022-0302(97)76215-5.

Wong, J. M., R. de Souza, C. W. Kendall, A. Emam, and D. J. Jenkins. 2006. Colonic health: Fermentation and short chain fatty acids. J. Clin. Gastroenterol. 40:235-243. https://doi.org/10.1097/ 00004836-200603000-00015.

Xu, T., N. Ma, Y. Wang, X. Shi, G. Chang, J. J. Loor, and X. Shen. 2018. Sodium butyrate supplementation alleviates the adaptive response to inflammation and modulates fatty acid metabolism in lipopolysaccharide-stimulated bovine hepatocytes. J. Agric. Food Chem. 66:6281-6290. https://doi.org/10.1021/acs.jafc.8b01439.

Yang, F., S. Zhang, X. Shang, L. Wang, H. Li, and X. Wang. 2018 Characteristics of quinolone-resistant Escherichia coli isolated from bovine mastitis in China. J. Dairy Sci. 101:6244-6252. https: //doi.org/10.3168/jds.2017-14156.

Zhu, Y., Y. Guan, J. J. Loor, X. Sha, D. N. Coleman, C. Zhang, X. Du, Z. Shi, X. Li, Z. Wang, G. Liu, and X. Li. 2019. Fatty acidinduced endoplasmic reticulum stress promoted lipid accumulation in calf hepatocytes, and endoplasmic reticulum stress existed in the liver of severe fatty liver cows. J. Dairy Sci. 102:7359-7370. https://doi.org/10.3168/jds.2018-16015. 